\title{
Numerical simulation of shear capacity of lightweight aggregate concrete stud connectors
}

\author{
Lin $\mathrm{Hao}^{1, *}$, Lei $\mathrm{Liu}^{1}$ and $\mathrm{Jian} \mathrm{Li}^{1}$ \\ ${ }^{1}$ School of Civil Engineering, Beijing Jiaotong University, 3 Shangyuancun, Beijing 100044, PR China.
}

\begin{abstract}
In order to study the mechanical properties of the stud connectors in lightweight aggregate concrete (LWAC), the finite element software ABAQUS was used to establish the push test models of ordinary concrete and LWAC, respectively. Through parameter analysis of 21 models, the influence of different parameters on the shear performance of LWAC stud connector was studied. Among them, concrete strength, stud diameter and stud strength have strong effects. Compared with stud connector in ordinary concrete, the LWAC stud connector enters the elastoplastic working stage earlier, the ultimate slip is slightly larger, the ductility is better, and the shear capacity is about $11 \%$ lower. Regression analysis was performed on the finite element calculation results, and the method for shear bearing capacity calculation of the stud connectors in LWAC is given.
\end{abstract}

\section{Introduction}

The steel-lightweight aggregate concrete composite beam is a new type of composite beam. In addition to the advantages of ordinary composite beams, lightweight aggregate concrete (LWAC) reduces the self-weight of the composite beam, which enhances the spanning capacity, and improves the seismic performance. Stud shear connectors play an important role in transmitting longitudinal shear force, resisting sliding, and lifting between the concrete and the steel in composite beams.

At present, relatively more in-depth researches were conducted on the steel-concrete composite beam connectors than mechanical properties of shear connectors in the steel-lightweight aggregate concrete composite beam. Generally, experimental testing and finite element numerical simulation are used to determine the shear bearing capacity of studs and related mechanical performance parameters. Ollgaard et al. ${ }^{[1]}$ analyzed the test results of ordinary and LWAC studs, and proposed a method for calculating the shear bearing capacity of studs, which are now commonly adopted in domestic and foreign codes; Dianzhong Liu ${ }^{[2]}$ designed and completed the pushout test of LWAC, discussed methods of calculating bearing capacity and deformation of the stud connector and obtained the load-slip relationship of the stud connector. Qiang Liu ${ }^{[3]}$ carried out a push-out experiment in LWAC and the results showed that the increase in studs diameter will increase the amount of relative slip. Yingqian $\mathrm{Liu}^{[4]}$ carried out an experimental study on steellight aggregate concrete stud connectors, and the results showed that the shear bearing capacity of LWAC stud connectors was greater than that is calculated according to EC4 ${ }^{[5]}$ Design value.

Current researches on the shear capacity evaluation of the LWAC beam stud connectors are not thorough and needs improvement. In order to further study the mechanical properties of stud connectors in LWAC, finite element models are simulated to analyze the factors affecting the stress and shear capacity of stud connectors in LWAC, and the method for shear bearing capacity calculation of stud connectors in LWAC is proposed, which provides reference for the future design of LWAC composite structures.

\section{Finite element model}

\subsection{Establish a finite element model}

In this paper, finite element model of pull-out test was used to study the mechanical properties of studs in LWAC and ordinary concrete(OC) composite beams, and the structural dimensions of push-out specimens are shown in Figure 1. The finite element model was established by ABAQUS software, as shown in Figure 2, and the rationality of the model was verified by comparing with the push-out test results in relevant references ${ }^{[6-7]}$. 


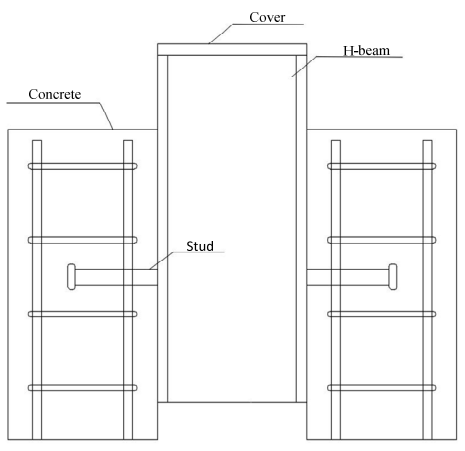

Figure 1. Pull-out experiment dimension.

The finite element model in this paper includes four parts: concrete, stud, H-beam and stirrups, of which the Hbeam, stud and concrete adopt C3D8R solid element, and the stirrups adopt T3D2 truss element. All parts adopt hexahedral-shaped units. The contact effect between the stud and the concrete slab is simulated in two parts: hard contact is used in the normal direction, and a penalty function with a friction factor of 0.25 is used in the tangent direction. The stud and the H-beam adopt are connected

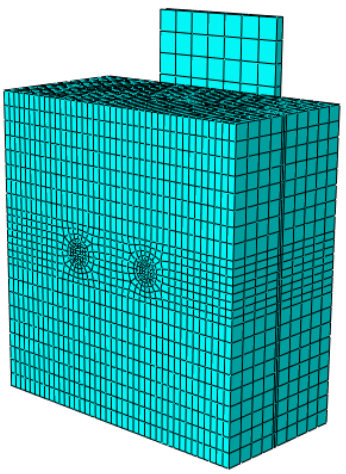

Figure 2. Schematic diagram of model meshing.

by using tie constraints. The steel bars are embedded in the concrete slab. According to the symmetry of the push-out test specimen, a 1/2 push-out test model is established for analysis. In order to analyze the influence of concrete type, strength, elastic modulus, stud diameter and stud strength on the ultimate bearing capacity of stud connectors, $21 \mathrm{FE}$ models were established and their respective parameters are shown in Table 1:

Table1. Model grouping and parameters.

\begin{tabular}{|c|c|c|c|c|}
\hline Model & Concrete type & $\begin{array}{c}\text { Compressive strength } \\
\text { of concrete(MPa) }\end{array}$ & $\begin{array}{c}\text { Stud diameters } \\
\mathrm{d}(\mathrm{mm})\end{array}$ & $\begin{array}{c}\text { Concrete modulus } \\
E_{c}(\mathrm{GPa})\end{array}$ \\
\hline PC1/2/3 & OC & 30 & $16 / 19 / 22$ & 30 \\
\hline PC4/5/6 & OC & 40 & $16 / 19 / 22$ & 32.5 \\
\hline PC7/8/9 & OC & 50 & $16 / 19 / 22$ & 34.5 \\
\hline PT1/2/3 & LWAC & 30 & $16 / 19 / 22$ & 21 \\
\hline PT4/5/6 & LWAC & 40 & $16 / 19 / 22$ & 24.3 \\
\hline PT7/8/9 & LWAC & 50 & $16 / 19 / 22$ & 27.1 \\
\hline PX1/2 & OC & 40 & $16 / 19$ & 32.5 \\
\hline PX3 & LWAC & 60 & 22 & 29.7 \\
\hline
\end{tabular}

\subsection{Material constitutive model}

The constitutive model of concrete plastic damage adopts the Sidiroff energy method ${ }^{[8]}$ with an additional correction coefficient. For ordinary concrete, the concrete stressstrain relationship in the specification "Code for design of concrete structure "[9] is adopted; For LWAC, the dimensionless LWAC uniaxial stress-strain relationship proposed by Zhenhai $\mathrm{GuO}^{[10]}$ is adopted. The constitutive model of H-beam and steel bars adopts an ideal elasticplastic model, and the stud adopts an idealized trilinear stress-strain model.

\subsection{Finite element verification}

FE model PX1 and PX2 are established based on data in Faxing Ding's research ${ }^{[6]}$, and FE model PX3 is established based on data in Xianguang Li's research ${ }^{[7]}$. The comparison between the load-slip curve of PX1 PX3 models and the load-slip curve given in the references are shown in Figure 3. Moreover, load and maximum shear force ratio of PX1 PX3 were also compared with the results from Buttry ${ }^{[11]}$ and Ollgaard ${ }^{[1]}$, as shown in Figure 4. It can be seen that the results from PX1 PX2 are close to the results in the reference papers, which indicates that the established FE models are legit and that any future analysis is reliable. 


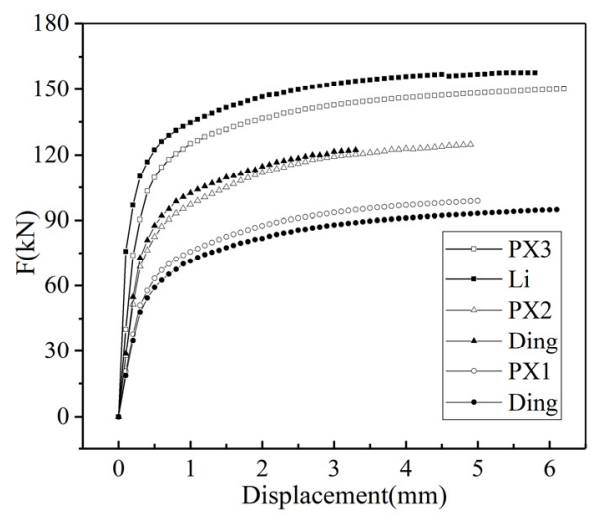

Figure 3. Load-slip curve of PX1 PX3 and the reference.

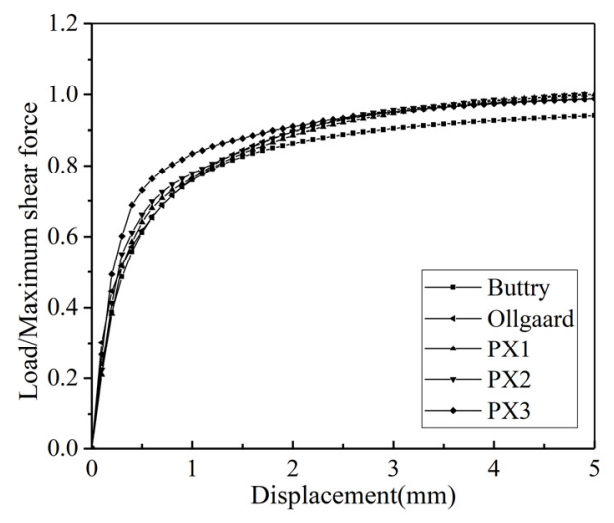

Figure 4. Comparison between PX1 PX3 and the reference.

\section{Discussion}

\subsection{Load-slip curve}
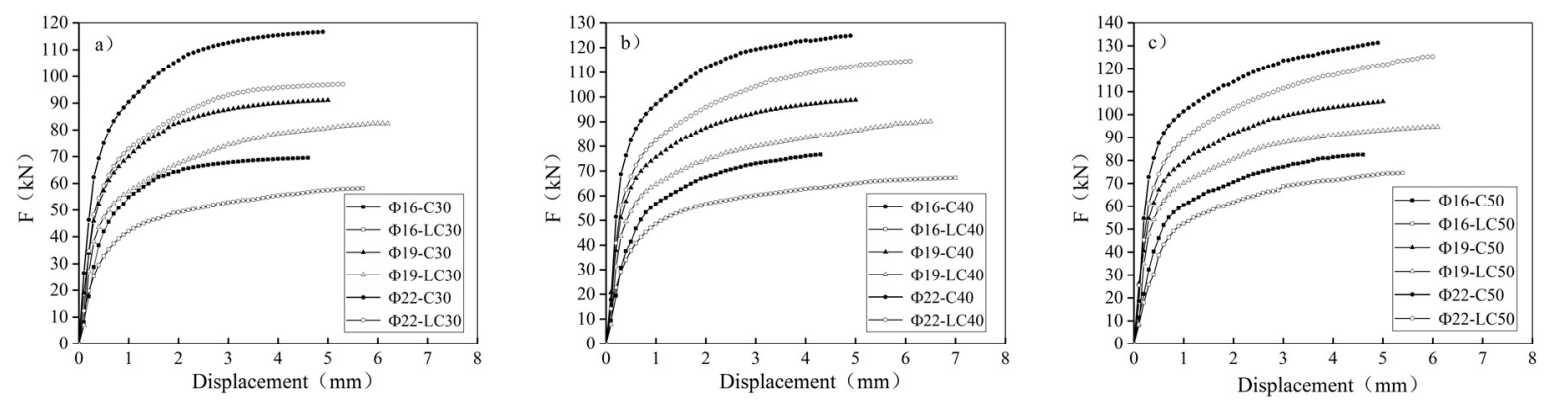

Figure 5. Load-slip curves for stud diameters 16,19 , and $22 \mathrm{~mm}$ with LWAC strengths of: a) $30 \mathrm{MPa}$ ) $40 \mathrm{MPa}$ c) $50 \mathrm{MPa}$.

As shown in Figure 5, the load-slip curves can be roughly divided into three stages: elastic stage, elasticplastic stage, and plastic failure stage. With the increase in concrete strengths, the load-slip curves of LWAC and ordinary concrete are becoming more and more similar. However, stud connectors have the lower bearing capacity in LWAC, but have better deformability and ductility.

\subsection{Factors affecting shear capacity}

This section analyzed the effect of concrete types, concrete strengths, stud diameter, tensile strength on the shear capacity of studs in LWAC beam. Shear capacities were calculated based on the established FE model. Table 2 shows the stud shear capacity of studs in model PC1 PC9 and PT1 PT9.

Table2. Stud shear capacity. (unit:kN)

\begin{tabular}{rccccccccc}
\hline & 1 & 2 & 3 & 4 & 5 & 6 & 7 & 8 & 9 \\
\hline PC & 69.50 & 91.06 & 114.65 & 76.58 & 97.74 & 124.84 & 82.38 & 105.68 & 131.34 \\
PT & 58.15 & 82.41 & 96.95 & 67.90 & 90.09 & 114.52 & 74.60 & 94.72 & 125.32 \\
PC/PT & 1.20 & 1.10 & 1.18 & 1.13 & 1.08 & 1.09 & 1.10 & 1.12 & 1.05 \\
\hline
\end{tabular}

3.2.1 Concrete type. According to Fig. 5 and Table 2, compared with ordinary concrete, the load of LWAC increases slowly with the increase of slip before reaching the ultimate bearing capacity after entering the elasticplastic stage, showing better ductile characteristics at failure. When other parameters are the same, the shear capacity of the studs in ordinary concrete is $11 \%$ greater than that of LWAC.

3.2.2 Concrete strength.It can be seen from Figure 6 that for both ordinary concrete and LWAC, the shear bearing capacity of studs increases as concrete strength increases. For stud diameter of $16 \mathrm{~mm}$, as the strength of ordinary concrete increased from C30 to C40 and C50, the ultimate bearing capacity increased by $10 \%$ and $19 \%$, 
respectively; as the strength of LWAC increased from C30 to $\mathrm{C} 40$ and $\mathrm{C} 50$, the ultimate bearing capacity increased by $17 \%$ and $28 \%$, respectively. This shows that increasing the strength of concrete can improve the ultimate bearing capacity of stud connectors, and that the effect of LWAC strength increase is more than ordinary concrete.

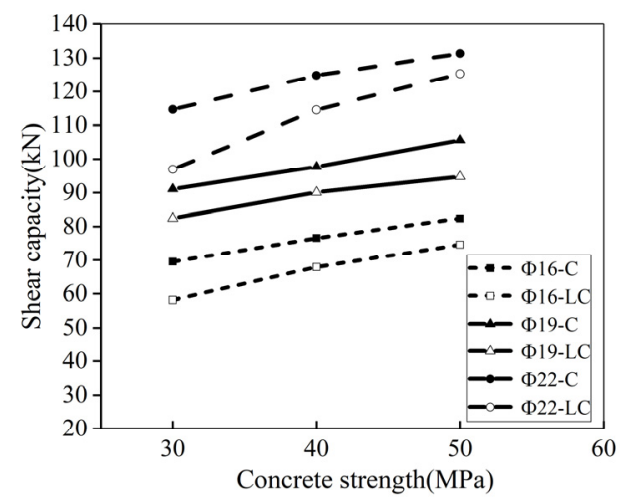

Figure 6. Concrete strength and stud shear capacity.

3.2.4 Stud diameter. Table 2 and Figure 8 show that for both LWAC and ordinary concrete, shear bearing capacity of the studs increases with the increase in stud diameter. For ordinary concrete with compressive strength of 40 $\mathrm{MPa}$, when the stud diameter is increased from $16 \mathrm{~mm}$ to $19 \mathrm{~mm}$ and $22 \mathrm{~mm}$, the shear capacity is improved by $27 \%$ and $63 \%$, respectively; whereas for LWAC with the same compressive strengths, as stud diameter increased from $16 \mathrm{~mm}$ to $19 \mathrm{~mm}$ and $22 \mathrm{~mm}$, the shear capacity is improved by $33 \%$ and $69 \%$, respectively. This shows that increasing stud diameter improves the ultimate bearing capacity of

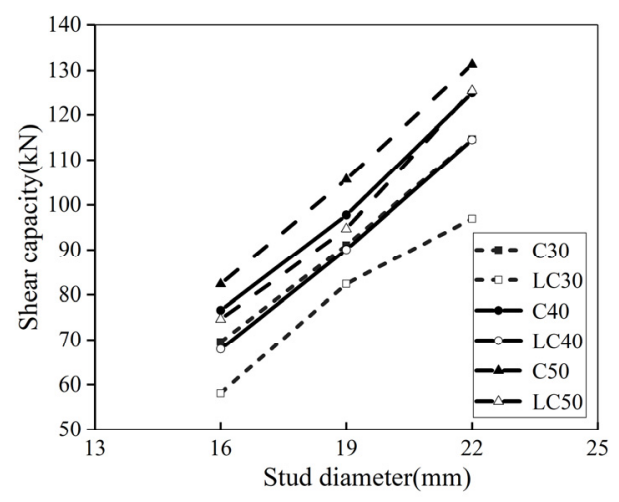

Figure 8. Stud diameter and shear capacity.

\section{Method for shear capacity calculation of LWAC stud connectors}

FE simulated results of PC1 PC9 and PT1 PT9 were
3.2.3 Concrete elastic modulus. Based on PT7 PT9 models, 6 more LWAC stud push-out FE models were established to analyze effects of different elastic modulus parameters. It can be seen from Figure 7 that the increase in elastic modulus of LWAC has little effect on the shear bearing capacity of the stud is.

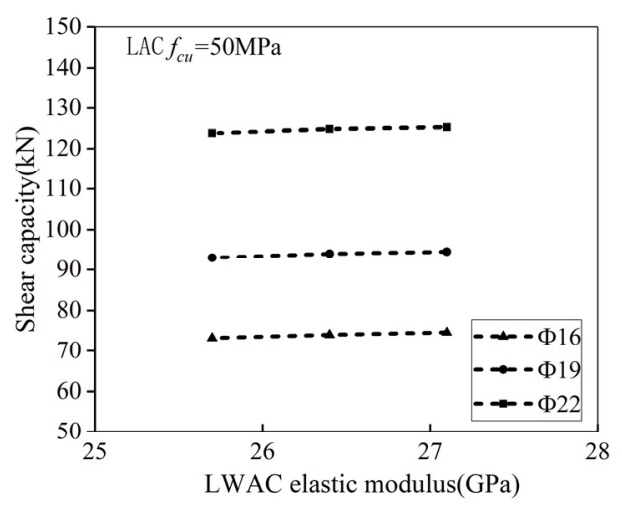

Figure 7. Elastic modulus and shear capacity of LWAC.

the stud connectors, and that the improvement is more significant in LWAC than in ordinary concrete.

3.2.5 Tensile strength of studs. Based on model PT7 PT9, 6 more FE stud push-out models were established to analyze the effects of different stud tensile strengths. The finite element simulation result of stud tensile strength and their respective shear capacity is shown in Figure 9. It shows that the stud shear capacity in LWAC increases almost linearly with the increase in stud tensile strength.

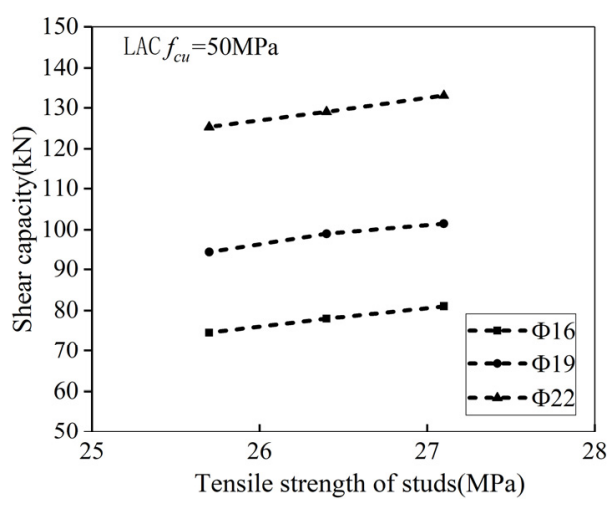

Figure 9. Stud tensile strength and shear capacity.

compared with theoretically calculated results using the methods specified in the Standard for design of steel structures $^{[12]}$, Code for design of steel and concrete composite bridges ${ }^{[13]}$ and Faxing Ding ${ }^{[9]}$, respectively. The results are shown in Table 3. It is noted that the FE result is 1.1 times larger than the theoretically calculated value. 
Table3. Comparison of FE and theoretical shear capacity results of studs

\begin{tabular}{clllllllll}
\hline LWAC & PT1 & PT2 & PT3 & PT4 & PT5 & PT6 & PT7 & PT8 & PT9 \\
\hline FE result & 58.15 & 82.41 & 96.95 & 67.9 & 90.09 & 114.52 & 74.6 & 94.72 & 125.32 \\
Ref. [12] & 47.35 & 66.78 & 89.53 & 56.27 & 79.35 & 106.4 & 56.27 & 79.35 & 106.4 \\
Ref. [13] & 47.76 & 65.94 & 88.41 & 49.55 & 69.88 & 93.68 & 51.79 & 73.03 & 97.91 \\
Ref. [2] & 67.85 & 89.13 & 109.7 & 79.06 & 102.1 & 124.1 & 89.01 & 113.3 & 136.5 \\
Theoretical result & 60.39 & 79.33 & 97.63 & 70.36 & 90.87 & 110.45 & 79.22 & 100.84 & 121.49 \\
\hline
\end{tabular}

The result in Ref. [6] and the FE result are the closest. Therefore, based on FE result and the theoretical calculated result based on Ref. [6], regression analysis was performed. The coefficient of determination $\mathrm{R}^{2}$ is 0.96 . Shear capacity at ductile failure of stud connectors in LWAC can be calculated using equation (1).

$$
P_{u}=0.89\left(0.2 d^{1.7}-10\right) f_{c u}^{0.8-0.15 \ln (d-10)}\left(0.002 \frac{f_{u}}{1.2}+0.24\right)
$$

Where, $\mathrm{P}_{\mathrm{u}}$ is the calculated shear capacity of the stud

connector; $\mathrm{d}$ is the stud diameter; $f_{c u}$ is concrete standard cube compressive strength; $f_{u}$ is the tensile strength of stud.

To verify the applicability of the formula, the ratio of the result calculated by equation (1) to the results obtained in references $[2,3,4,7]$ is analyzed. The average value of the abovementioned ratio is $\mathrm{w}$ and the dispersion coefficient is Vs. Results are shown in Table 4. Comparison results show that the average value is close to and that the dispersion coefficient is small, which proves that the proposed equation yields satisfactory result.

Shear Bearing Capacity of Single LWAC Stud

\begin{tabular}{cccccc}
\hline Ratio & Ref. [2] & Ref. [3] & Ref. [7] & Ref. [4] & Mean \\
\hline W & 0.977 & 1.049 & 1.134 & 1.142 & 1.075 \\
Vs & 0.055 & 0.121 & 0.084 & 0.058 & 0.079 \\
\hline
\end{tabular}

\section{Conclusion}

Finite element analysis software ABAQUS was used to simulate the push-out test of ordinary and LWAC stud connectors. Considering the influence of different parameters, the load-slip curve of stud connectors is studied, and the following conclusions are made:

1) Compared with ordinary concrete studs, the ultimate bearing capacity of LWAC is reduced by about $11 \%$. The shear capacity of LWAC studs increases with the increase in concrete strength, stud diameter as well as tensile strength.

2) Compared with the load-slip curve of ordinary concrete stud connectors under the same parameters, the elastic working phase of the LWAC stud connector is similar; it enters the elastic-plastic working phase earlier; the limit slip is larger, showing good ductility.

3) Through regression analysis of the FE model results, the equation of calculating shear capacity of LWAC stud connector was proposed.

\section{Acknowledgments}

Authors would like to acknowledge the financial support of the research program KCL15022530 "Research on Development and Application Technology of Lightweight High Strength Concrete Materials for Bridges".

\section{References}

1. Ollgaard J G, Slutter R G and Fisher J W 1971 Shear
Strength of Stud Connectors in Lightweight and Normal-Weight Concrete Aisc Eng Journal 8 55-64

2. Liu DZ 2008 Calculating method and experimental investing for steel-lightweight aggregate concrete composite beam Jilin University

3. Liu Q and Lu CD 2009 A study on carrying capacity of studs between the steel and the lightweigh aggregate concrete Journal of Suzhou University of Science and Technology (Engineering and Technology ) 22 45-7

4. Liu YQ 2018 Highway 063 73-6

5. Structural Eurocodes 2001 EN 1994-1-1 Eurocode4: Design of composite steel and concretestructures, Part 1-1

6. Ding FX, Ni M, Gong YZ, Yu ZW and Zhou LC 2014 Experimental study on slip behavior and calculation of shear bearing capacity for shear stud connectors Journal of Building Structures 35 98-106

7. Li Xianguang, Liu Yingqian and $\mathrm{Xu}$ Haiying World Bridges 42 62-5

8. Sidoroff F 1981 Description of Anisotropic Damage Application to Elasticity: Physical

Non-Linearities in Structural Analysis

9. Ministry of Construction of the People's Republic of China 2010 GB 50010-2010 Code for Design of Concrete Structures China Architecture \& Building Press

10. Guo ZH 1997 Concrete strength and deformation test basis and constitutive relationship TsingHua University Press

11. Buttry K E K E 1965 Behavior of stud shear 
connectors in lightweight and normal-weight concrete

12. Ministry of Construction of the People's Republic of China 2017 GB50017-2017 Standard for design of steel structures China Architecture \& Building Press

13. Ministry of Construction of the People's Republic of China 2014 GB 50917-2013 Code for design of steel and concrete composite bridges China Planning Press 